\title{
Tam đề nan giải phát triển công nghiệp bền vững
}

\author{
Nguyễn Thị Quỳnh Yến \\ Ritsumeikan Asia Pacific University, Beppu, Nhật Bản \\ Khoa học \& Phát triển
}

$11 / 12 / 201915: 16$

KH\&PT (http://khoahocphattrien.vn/khoa-hoc/tam-de-nan-giai-phat-trien-cong-nghiepben-vung/20191211032440832p1c160.htm) -- Bài nghiên cứu của nhóm tác giả người Việt đánh giá hiệu quả của chính sách phát triển xanh đối với Kitakyushu, một thành phố công nghiệp nặng nhưng nổi tiếng với khả năng kiểm soát ô nhiễm môi trường, đã lọt vào Top Trending của tạp chí Palgrave Communications thuộc Nature Research, không lâu sau khi được công bố.

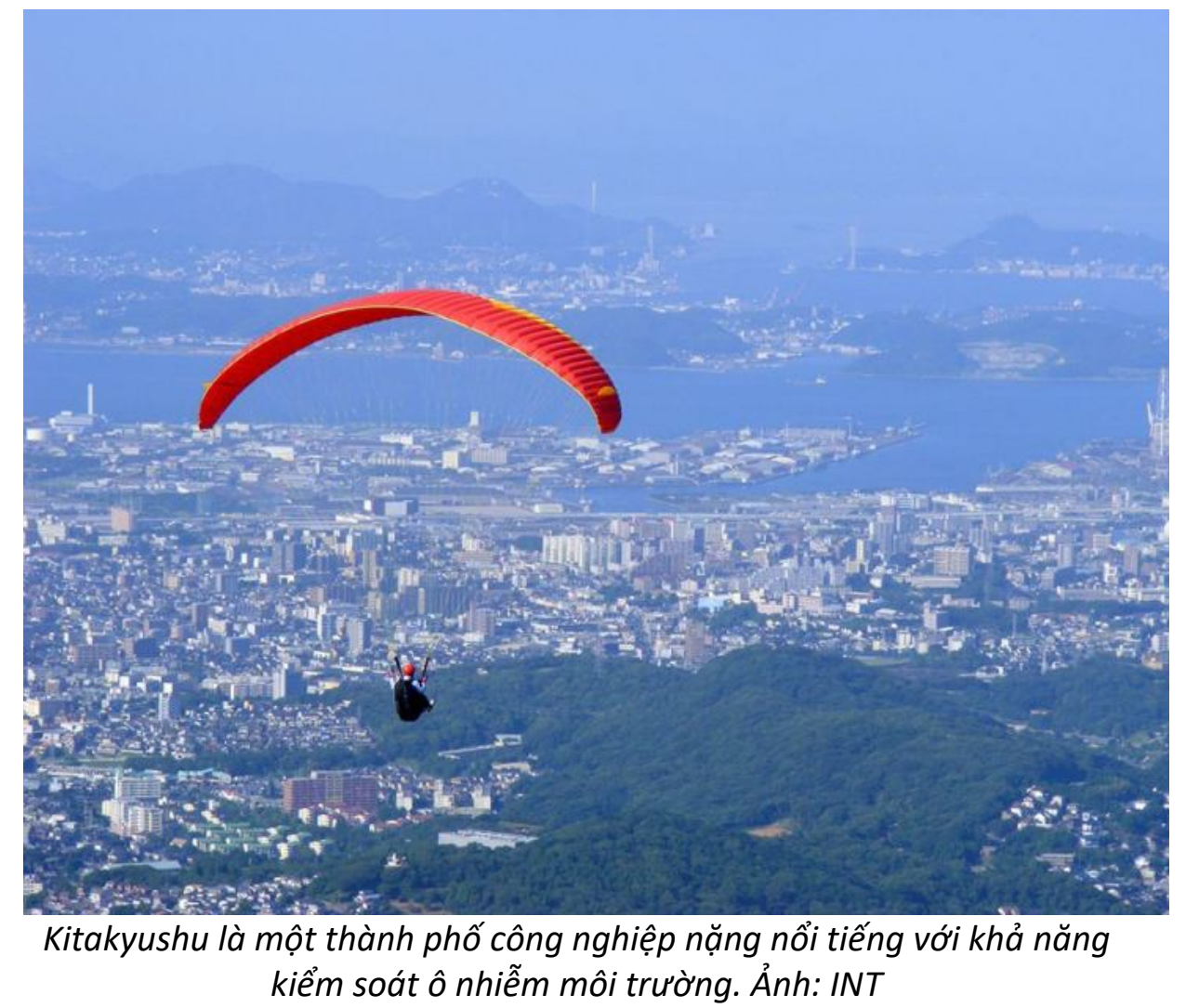

Trong kỷ nguyên khủng hoảng khí hậu, phát triển công nghiệp đồng thời giảm thiểu tác động nguy hại đến môi sinh trở thành một trong những mục tiêu quan trọng và khẩn 
cấp. Trên thế giới, có 4 thành phố tiêu biểu, thuộc các quốc gia phát triển nhất, được chọn làm mô hình thành phố 'xanh' bởi Tổ chức Hợp tác và Phát triển Kinh Tế (OECD), bao gồm Stockholm, Chicago, Paris, Kitakyushu. Trong đó, Kitakyushu (Nhật Bản) - thành phố công nghiệp nặng nổi tiếng với khả năng kiểm soát ô nhiễm môi trường - có tiềm năng trở thành hình mẫu để các quốc gia trong khu vực tham khảo về các chính sách phát triển "xanh".

Mới đây, một nhóm các nhà nghiên cứu Việt Nam đã đánh giá hiệu quả của chính sách phát triển xanh đối với thành phố Kitakyushu và đưa ra các gợi ý cho các thành phố đang theo đuổi mô hình tương tự, đặc biệt là tại các quốc gia đang phát triển. Công trình nghiên cứu với tiêu đề: "The trilemma of sustainable industrial growth: evidence from a piloting OECD green city" vừa được xuất bản trên tạp chí Palgrave Communications, thuộc Nature Research, và chỉ sau bốn ngày đã lọt top các bài được quan tâm nhiều nhất (Top Trending).

Nhóm tác giả chủ yếu bao gồm các nghiên cứu viên của Trung tâm ISR thuộc Trường ĐH Phenikaa, trong đó 3 tác giả trẻ đều đang hoàn thành chương trình cao học và tiến sỹ tại Nhật: Nguyễn Minh Hoàng, Hồ Mạnh Tùng và Nguyễn Tô Hồng Kông. Các nghiên cứu viên hoàn thành ấn phẩm dưới sự dẫn dắt của TS. Vương Quân Hoàng.

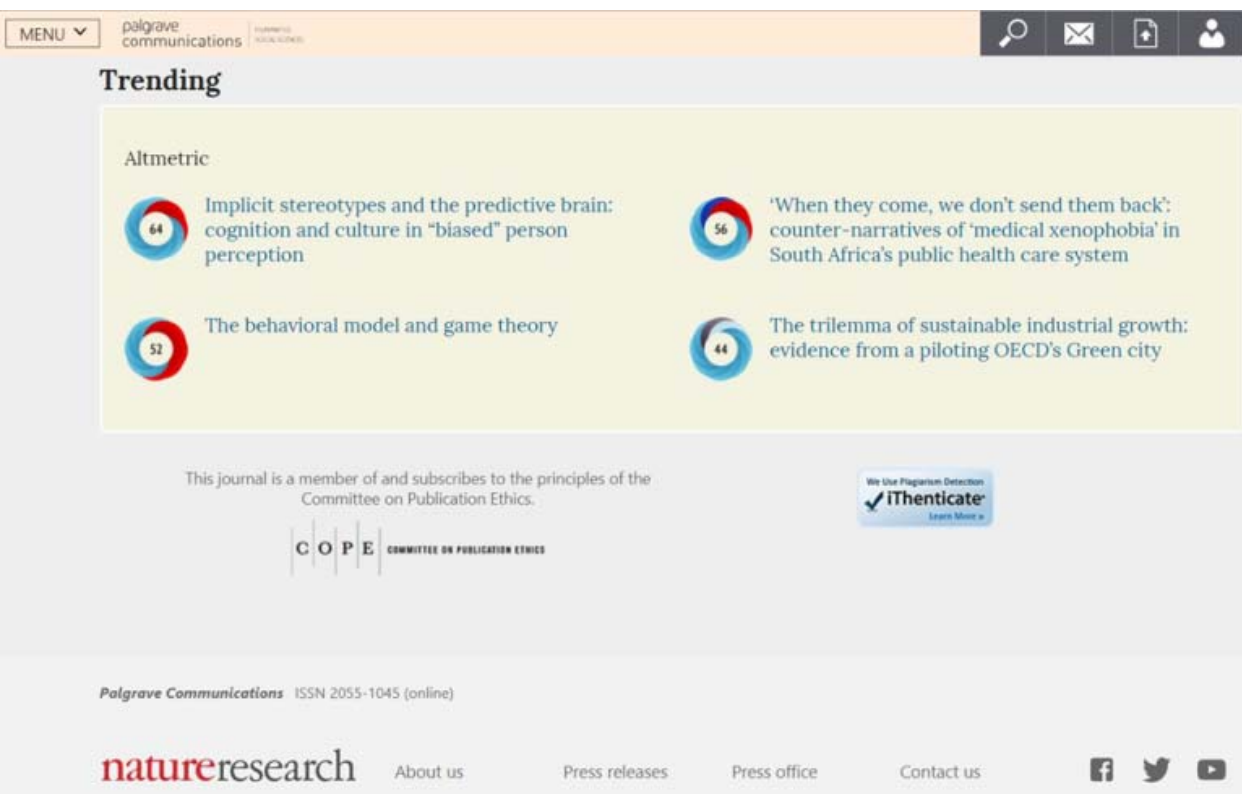

Bài nghiên cứu của nhóm tác giả Việt Nam lọt Top Trending chỉ sau bốn ngày được đăng. Ảnh chụp màn hình: QY 
Bài nghiên cứu đánh giá lại dáng điệu và động học của lý thuyết "Environmental Kuznets curve" (Đường cong Kuznets về môi trường - EKC, thường được sử dụng để thể hiện mối quan hệ giữa tăng trưởng kinh tế và chất lượng môi trường) với bộ dữ liệu gần 50 năm để tìm hiểu mối liên hệ giữa quy mô doanh nghiệp trong ngành công nghiệp, diện tích đường được xây dựng, và năm loại khí thải ô nhiễm tại thành phố Kitakyushu (bụi, khí $\mathrm{CO}$, khí $\mathrm{NO}_{2}$, sương mù quan hóa, và khí SOx).

Kết quả nghiên cứu đã chỉ ra các chính sách phát triển xanh có ảnh hưởng tích cực đến phát triển công nghiệp, đồng thời làm giảm khí thải tại thành phố Kitakyushu (cụ thể là nồng độ khí $\mathrm{NO}_{2}$ và khí $\mathrm{CO}$ ), như dưới đây:

1. Giám sát và kiểm soát nghiêm ngặt nồng độ khí thải trong không khí. Đồng thời thực hiện các chính sách hỗ trợ tài chính cho doanh nghiệp.

2. Đẩy mạnh hợp tác giữa chính phủ, doanh nghiệp, và các trường đại học để phát triển và đổi mới công nghệ tiết kiệm năng lượng và giảm lượng khí thải.

3. Ảnh hưởng của kinh tế quy mô từ tăng trưởng của các công ty công nghiệp trong khu vực và lân cận, động học thay đổi qua thời gian của tác động.

4. Chuyển đổi nguồn năng lượng từ than và dầu sang khí tự nhiên và các nguồn năng lượng tái tạo.

Tuy nhiên, ngay cả việc chuyển đổi sang phát triển công nghiệp "sạch hơn" cũng có giới hạn của nó, dựa trên dáng điệu EKC. Như vậy, khái niệm "xanh" và "sạch" chỉ có hiệu lực cho từng giai đoạn, và phụ thuộc cũng như chịu sự hạn chế của chính sách giám sát và kiểm soát ô nhiễm. Ví dụ, tại Kitakyushu, thời gian gần đây, các công ty công nghiệp nặng lớn, như sản xuất sắt thép và hóa chất, có xu hướng đặt hàng bên ngoài từ các công ty nhỏ hơn. Việc này làm tăng cường ô nhiễm bụi và sương mù quang hóa do hiện nay chưa có các chính sách kiểm soát ô nhiễm từ các công ty vừa và nhỏ hiệu quả.

Một kết quả đáng chú ý khác của bài nghiên cứu là các ảnh hưởng hai chiều, cả tiêu cực lẫn tích cực, từ việc phát triển đồng thời ngành tái chế và hệ thống cơ sở hạ tầng đường bộ tại Kitakyushu. Một mặt, hệ thống cơ sở hạ tầng phát triển có thể thúc đẩy nền công nghiệp tái chế, qua đó giảm phát thải khí nhà kính. Mặt khác, sự phát triển của hệ thống cơ sở hạ tầng cũng dẫn đến sự mở rộng khó kiểm soát của diện tích đô thị và nhu cầu đi lại của người dân, dẫn đến làm tăng ô nhiễm không khí do lượng phát thải của phương tiện giao thông. Nhưng nếu hệ thống cơ sở hạ tầng không được phát triển đầy đủ, ngành công nghiệp tái chế không thể tăng trưởng và mở rộng do thiếu nguyên liệu, điều này không chỉ khiến cho các nỗ lực giảm thải khí nhà kính gặp nhiều khó khăn, mà còn làm giảm thiểu lợi ích kinh tế vùng. Vì thế, các tác giả gọi đó là "tam đề nan giải" (trilemma) trong việc thúc đẩy công nghiệp phát triển bền vững. 
Ngoài các giá trị khuyến nghị chính sách thúc đẩy công nghiệp phát triển bền vững cho thành phố Kitakyushu, vùng Kyushu và Nhật Bản, bài nghiên cứu cũng mang lại những đúc kết có ích cho các quốc gia khác tham khảo trong quá trình xây dựng chính sách môi trường.

\section{Tài liệu tham khảo:}

Vuong, Q., Ho, M., Nguyen, T. H. K, Nguyen, M. H. (2019). The trilemma of sustainable industrial growth: evidence from a piloting OECD's Green city. Palgrave Communications, 5, 156, doi: 10.1057/s41599-019-0369-8

Vuong QH (2018). The (ir)rational consideration of the cost of science in transition economies. Nature Human Behaviour, 2(1), 5, https://doi.org/10.1038/s41562017-0281-4. 